\title{
Echinoderms as indicators of brine discharge impacts
}

\author{
Yolanda Fernández-Torquemada*, José Miguel González-Correa, José Luis \\ Sánchez-Lizaso \\ Department of Marine Sciences and Applied Biology, University of Alicante, PO Box 99, E-03080 Alicante, Spain \\ Tel.+34 96590 3400/Ext. 2916; Fax: +34 96590 9840; email: yolanda.fernandez@ua.es
}

Received 28 February 2012; Accepted 25 July 2012

\section{Introduction}

Desalination of seawater has acquired considerable importance in recent decades in most of the countries of the Mediterranean basin and also in other regions $[1,2]$. As a consequence, the study of its possible impacts on the marine environment has become particularly relevant in last years [3-8]. The most employed desalination technique in most countries is reverse osmosis, which produces a considerable volume of rejected water relatively concentrated in dissolved salts (44-70 psu). This concentrate used to be discharged directly into the sea [9], forming a dense plume that sinks to the seafloor and extends horizontally following the slope of the sea bottom bathymetry [3]. Its spatial dispersion depends on the characteristics of the desalination plant and its reject brine and

*Corresponding author. on the physical conditions (i.e bathymetry, hydrodynamics, etc.) of the receiving marine environment. Brine dispersion may be significantly reduced if desalination plant discharges are previously diluted with sewage treatment plant discharges, power plant cooling water discharges or seawater [10]. On the other hand, brine spreading can also be minimized by selecting an appropriate discharge location or by establishing a carefully designed monitoring programme in order to assess the brine plume distribution over time and taking appropriate measurements when necessary [11].

Moreover, the elevated salinities associated to a desalination discharge may produce negative effects and mortality on benthic communities, mainly on marine organisms that live fixed or move slowly on the sea floor and are unable to escape from the salinity increment. These negative effects will depend 
upon the maximum salinities reached, persistence of these salinities and species sensitivity. In the Mediterranean Sea, some studies have detected detrimental effects of brine discharges on seagrasses [3,5] and infaunal communities [6-8], but studies related with epifaunal organisms, such as echinoderms, are currently scarce [4].

Most common echinoderms include echinoids (sea urchins), holothuroids (sea cucumbers) and asteroids (starfishes); marine animals are widely distributed in all oceans from seashore to all depths. These organisms are used to be considered as important ecosystem engineers and bioturbators, in addition to form a significant part of the food chain as prey for several carnivorous animals [12].

Echinoderms have been used as biological indicators and biomarkers of marine contamination, with many extensive studies undertaken over the years. They are useful bioindicators due to their abundance, wide distribution, ecological relevance, benthic behaviour, rapid response and high sensitivity to the presence of many types of pollutants [13]. About its salinity tolerance, echinoderms are commonly considered to be strictly marine species. Consequently, they are expected to be very sensitive to salinity variations, particularly during larval stages of their life cycles. However, the main researches about responses of echinoderms to changes in salinity have been focused on decreases in salinity rather than increases, with only a known experimental study in which there was detected a very low tolerance of these organisms to increases in salinity [14]. In another study, a significant absence of the echinoderm communities in the vicinity of a desalination discharge was observed [5].

Therefore, it can be considered that these organisms could serve as good indicators for detecting zones of affection associated with a hypersaline desalination discharge. In the present work, we report the effects of a SWRO brine discharge on populations of echinoderms habiting a Posidonia oceanica meadow for nine years and we examine the use of these organisms as early warning indicators of the impact of brine discharges and its potential application to the management of desalination discharges.

\section{Material and methods}

\subsection{Study site and description of the desalination plant}

The study was carried out in a degraded P. oceanica meadow located at Alicante (W Mediterranean, Spain; Fig. 1), from June 2003 to June 2011. This meadow has received (more or less continuously) the brine discharge from the New Channel Alicante I desalination plant.

This SWRO desalination plant began operations in September 2003. Incoming water was obtained from beach wells and the plant initially had a maximum capacity of $50,000 \mathrm{~m}^{3} \mathrm{~d}^{-1}$ with a recovery of $42-44 \%$, which represented a discharge of $66,000 \mathrm{~m}^{3} \mathrm{~d}^{-1}$ with a salinity of $68 \mathrm{psu}$. However, in January 2006, it was enlarged to produce up to $68,000 \mathrm{~m}^{3} \mathrm{~d}^{-1}$ and a second desalination plant with the same capacity started to operate in summer 2008 when the discharge was doubled. Following this increase in capacity, the option of diluting the brine with seawater prior to discharge was adopted. The dilution of the brine is not constant and has been oscillating between 1.5 and 5 parts of seawater to each part of brine according to the results of the monitoring programme.

Brine discharge is located directly on the shoreline south of Alicante city, since this is an area degraded by previous impacts. $P$. oceanica meadow in this area is in regression; its upper limit was at $-13 \mathrm{~m}$ depth in 1984, whilst it moved to $-16 \mathrm{~m}$ depth in 2007 . The meadow at the upper limit, which continues in regression, is formed by small patches of highly dispersed $P$. oceanica and surrounded by dead Posidonia matte covered by the muddy sediments and the macroalgae Caulerpa racemosa, Caulerpa prolifera and Dictyopteris $s p$.

\subsection{Echinoderms density estimate}

Echinoderms associated to a $P$. oceanica meadow were studied at three stations (Fig. 1) in the upper limit of the seagrass meadow $(-16 \mathrm{~m})$ : one in front of the desalination plant discharge (desalination station $=D$ ); one two kilometres to the north (north station $=N$ ); and the other one two kilometres south (south station $=S$ ). At each station, echinoderm assemblages were visually surveyed by scuba diving along 10 narrow transects $(10 \times 1 \mathrm{~m})$, recording the abundances for each species encountered. This sampling was repeated before (year 2003) and after the desalination plant began to operate (from 2004 to 2011), once a year and in the summer season.

\subsection{Environmental data acquisition and analysis}

In order to know the temporal brine dispersion in the area, we located three conductivity and temperature sensors (CTs) at study locations (Fig. 1). These CTs, which incorporated data loggers, were moored near the sea bottom for the continuous and simultaneous measurement of salinity and temperature at 


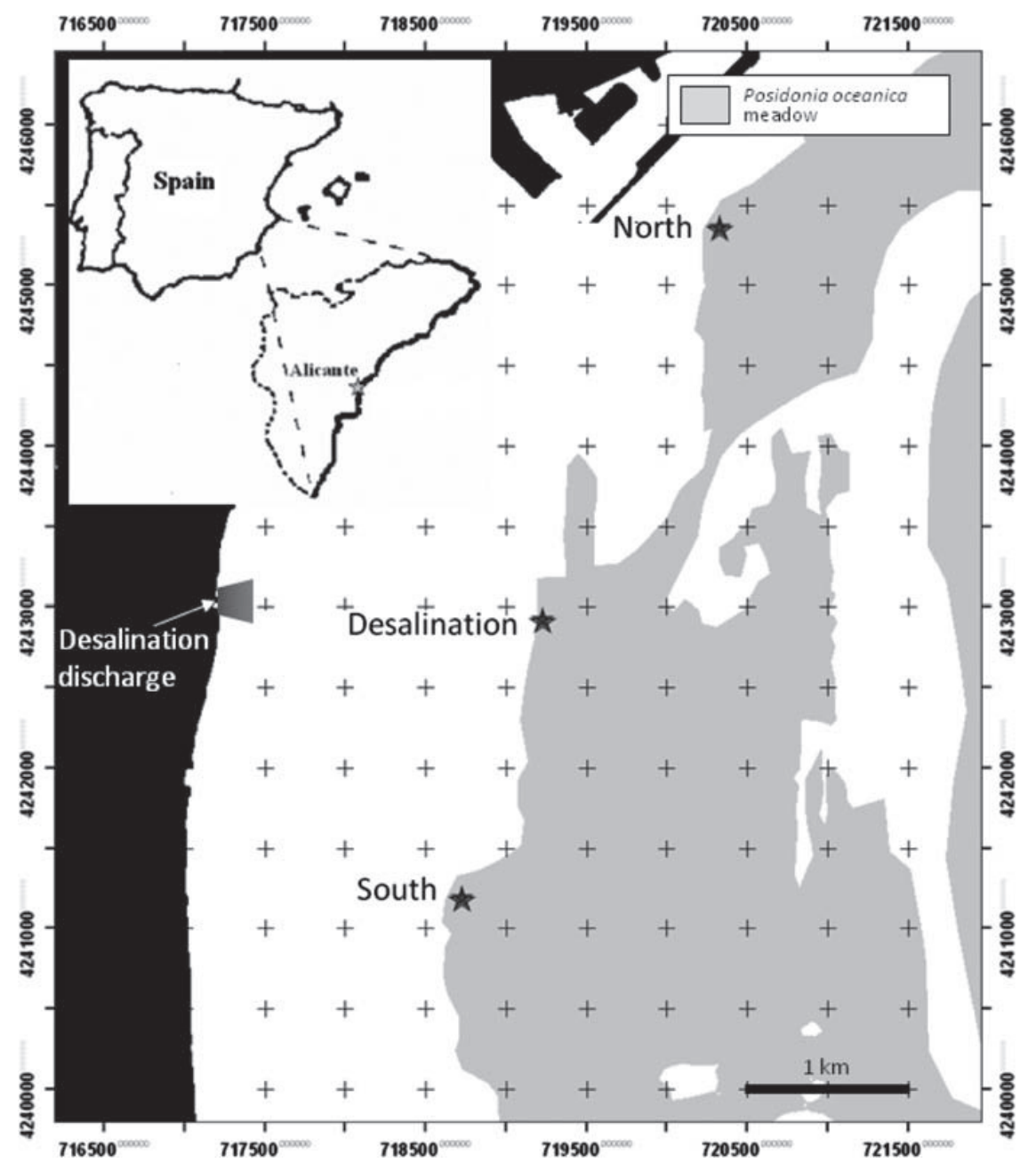

Fig. 1. Map of the study area showing the sampling stations and the desalination brine discharge.

multiple locations with great accuracy. We selected sample intervals of $10 \mathrm{~min}$ and data were acquired monthly to avoid fouling interferences in the sensors.

5 At the same time, another CT was located directly before the discharge to monitor changes in the effluent salinity due to variations in the previous dilution.

On the other hand, and due to the relevance of sediment characteristics on echinoderm assemblages, we collected three core samples at each locality for particle size and organic matter content analysis, before and after desalination activity. Immediately after its collection, $\mathrm{pH}$ was measured at intact sediment cores utilising a pH-meter. Then, the granulometric analysis was performed following Buchanan's methodology [15] and organic matter content was estimated by loss of mass ignition after calcining a subsample at $400{ }^{\circ} \mathrm{C}$ for $4 \mathrm{~h}$.

\subsection{Statistical analysis}

Changes in the echinoderms populations at the different stations were analysed using univariate techniques. An asymmetrical analysis of variance (ANOVA) was employed, with a linear model consistent on two fixed orthogonal factors: time (nine years portioned into three fractions: one year before the desalination plant began operations, two years with a brine discharge without seawater by-passing; and the last six years with a predilution of brine by-passing seawater) and station (three localities with a presumably different degree of impact), with $n=10$ observations per combination of factor levels. To detect any effect of the brine discharge on echinoderms, we were interested in the interaction among stations: time before desalination operation and thereafter, without and with a brine dilution (Table 3 ). 


\begin{tabular}{|lrr}
\hline TDWT & \multirow{2}{*}{ CE: YS QA: GJ } \\
716609 & Initial & 2 August 2012 \\
\hline
\end{tabular}

When ANOVA identified a significant difference for any factor or interaction, the multiple comparison post hoc test Student-Newman-Keuls (SNK) was applied to determine specific treatment differences. Homogeneity of variance had previously been verified using the Cochran test. All calculations were performed using the GMAV.5 software (University of Sydney, Australia) with a minimum significance level established at $p<0.05$ [16].

\section{Results}

Salinity data recorded in the area previous to the desalination plant beginning operations were 36.9$38.2 \mathrm{psu}$, with an average salinity of $37.5 \mathrm{psu}$ (Table 1 ). During the first two years of plant operation, brine was discharged without a previous dilution and we detected an increment of salinity on the localities situated in front of the desalination discharge and that placed in the south, reaching maximum and average salinity 0.4 and 0.3 psu higher than ambient salinity. Those increments were persistent on time. If we assume that salinities above $38.3 \mathrm{psu}$ are related with desalination plant discharge (since we never measured these values in the control locality) at the station in front of the desalination plant, the influence of the discharge was observed during more than $58 \%$ of the time, while at southern station $31 \%$ of data exceeded 38.3 psu (Table 1). On the other hand, when the desalination plant was enlarged and its brine was diluted previously to its discharge, all these values were reduced (Table 1).

Sediment characteristics in the area were quite homogeneous (Table 2). The $\mathrm{pH}$ values ranged between 7.5 and 7.7 at all stations and at both sampling periods. At the same time, organic matter contents ranged between 6.4 and $8.2 \%$. Most fine sedimentary fraction dominated at all stations, with a percentage of mud of $40-61 \%$ and $25-35 \%$ of fine sands.

With regard to the echinoderm community, the most abundant species observed in this study were sea cucumbers from the genus Holothuria spp and the sea star, Echinaster sepositus, and rarely few individuals of Paracentrotus lividus, Amphiura chiajei, Genocidaris maculata and Marthasteria glacialis. On the other hand, during the two first years of operation (2004-2005), we observed a disappearance of echinoderms in the seagrass meadows with influence of the brine discharge. From 2006 to 2011, when the desalination discharge was previously diluted and the influence of the discharge was reduced, we observed that echinoderms appeared again at all the localities, reaching values of $0.04-0.08$ individuals per $\mathrm{m}^{2}$ similar to that observed before the commencement of the activity. However, significant changes were observed only at the locality situated in front of the brine discharge (Fig. 2 and Table 3).

\section{Discussion}

In the present study, an initial disappearance of echinoderms at localities affected by an increment of salinity associated to a desalination plant has been observed. When the brine discharge was diluted and we observed a lower increase of salinity at the seagrass meadow, echinoderms densities increased to values similar to the initial ones. These changes in echinoderms communities are explained by salinity changes, because the rest of the abiotic factors analysed $(\mathrm{pH}$, organic matter and particle size composition of sediments) were similar at all the stations and remained quite stable during the time of this study. Echinoderm disappearance was detected when salinities exceeded maximum natural salinities ( $38.3 \mathrm{psu}$ ) for more than $31-58 \%$ of the time, although average

Table 1

Salinity values recorded with the CTs on the sampling locations, before (2003) and after (2004-2011) desalination plant operation

\begin{tabular}{|c|c|c|c|c|c|c|c|c|}
\hline \multirow[t]{2}{*}{ Desalination plant operation } & \multirow[t]{2}{*}{ Brine dilution } & \multirow[t]{2}{*}{ Control salinity (psu) } & \multicolumn{3}{|c|}{$\begin{array}{l}\text { Salinity } \\
\text { increment } \\
\text { respect to } \\
\text { control (psu) }\end{array}$} & \multicolumn{3}{|c|}{$\begin{array}{l}\text { Salinity data above } \\
38.3 \mathrm{psu}(\%)\end{array}$} \\
\hline & & & $N$ & $D$ & $S$ & $\bar{N}$ & $D$ & $S$ \\
\hline Before & & 37.5 & 0 & 0 & 0 & 0 & 0 & 0 \\
\hline \multirow[t]{2}{*}{ After } & Undiluted brine & 37.6 & 0 & 0.4 & 0.3 & 0.2 & 58.3 & 31.1 \\
\hline & Diluted brine & 37.7 & 0 & 0.2 & 0.1 & 0.2 & 20 & 14.3 \\
\hline
\end{tabular}

Note: $N=$ north $D=$ desalination and $S=$ south stations. 
Table 2

Summary of abiotic factors of sediment at each station, before and after desalination plant operation

\begin{tabular}{|c|c|c|c|c|}
\hline \multirow[t]{2}{*}{ Sediment characteristics } & \multirow[t]{2}{*}{ Desalination plant operation } & \multicolumn{3}{|l|}{ Station } \\
\hline & & North & Desalination & South \\
\hline \multirow[t]{2}{*}{$\mathrm{pH}$} & Before & $7.57 \pm 0.04$ & $7.51 \pm 0.03$ & $7.71 \pm 0.11$ \\
\hline & After & $7.58 \pm 0.03$ & $7.47 \pm 0.02$ & $7.62 \pm 0.03$ \\
\hline \multirow[t]{2}{*}{ O.M. (\%) } & Before & $8.24 \pm 0.55$ & $7.99 \pm 0.64$ & $7.31 \pm 0.45$ \\
\hline & After & $6.44 \pm 0.49$ & $7.23 \pm 0.67$ & $8.05 \pm 0.67$ \\
\hline \multirow[t]{2}{*}{ Mud (\%) } & Before & $61.47 \pm 0.79$ & $43.11 \pm 4.38$ & $39.66 \pm 7.14$ \\
\hline & After & $51.65 \pm 3.68$ & $41.56 \pm 1.61$ & $41.39 \pm 2.09$ \\
\hline \multirow[t]{2}{*}{ Fine sand $(\%)$} & Before & $27.53 \pm 2.21$ & $25.31 \pm 1.70$ & $35.48 \pm 2.35$ \\
\hline & After & $32.63 \pm 2.23$ & $28.62 \pm 1.49$ & $28.49 \pm 3.10$ \\
\hline \multirow[t]{2}{*}{ Medium sand (\%) } & Before & $3.69 \pm 0.48$ & $6.29 \pm 0.11$ & $5.02 \pm 0.38$ \\
\hline & After & $5.12 \pm 0.37$ & $7.88 \pm 0.48$ & $8.59 \pm 0.97$ \\
\hline \multirow[t]{2}{*}{ Coarse sand (\%) } & Before & $3.45 \pm 0.63$ & $12.79 \pm 2.24$ & $9.85 \pm 2.53$ \\
\hline & After & $6.08 \pm 0.91$ & $13.10 \pm 0.29$ & $12.84 \pm 0.22$ \\
\hline \multirow[t]{2}{*}{ Gravel (\%) } & Before & $3.87 \pm 1.46$ & $12.50 \pm 1.62$ & $9.99 \pm 2.41$ \\
\hline & After & $4.51 \pm 0.71$ & $8.84 \pm 0.72$ & $8.68 \pm 2.67$ \\
\hline
\end{tabular}

Note: O.M. =organic matter; mud $<63 \mu \mathrm{m}$, fine sand $=63-250 \mu \mathrm{m}$, medium sand $=250-500 \mu \mathrm{m}$, coarse sand $=500 \mu \mathrm{m}-2 \mathrm{~mm}$ and gravel $>2 \mathrm{~mm}$.

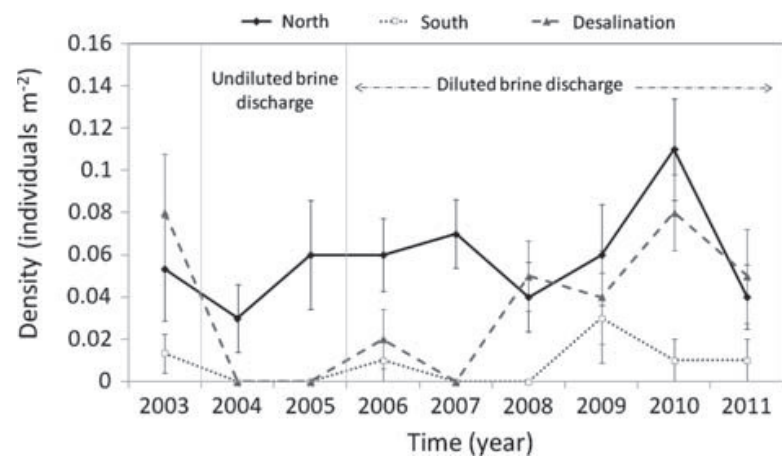

Fig. 2. Evolution of the average density of echinoderms (number of individuals per $\mathrm{m}^{2}$ ) at the three stations on the upper limit of Posidonia oceanica meadow (north, desalination and south) during the nine years of sampling (bars represent standard errors).

salinity was only increased $0.3-0.4 \mathrm{psu}$ and still remains inside the natural variation range. Regardless of the increased production, the brine dilution salinities higher than 38.3 psu were detected only during 14-20\% of the time and echinoderms reappeared in the previously affected localities after two years of absence.

Echinoderms are considered as good bioindicator organisms because of their abundance and their wide distribution. They have been selected for this study because they are osmoconformer organisms, and therefore they are not able to regulate their osmotic pressure [11], and several studies have shown that these organisms can tolerate only a narrow range of salinities $[17,18]$. Salinity also may play a vital role in echinoderms larval development [19]. Our results suggest that high salinity diminishes echinoderms density in affected areas, but we cannot conclude whether the high salinities have produced an increment in the mortality of these species or induced its displacement to other areas outside the influence of the brine. In any case, echinoderms are very important elements in the seagrass food web as predators (some sea stars) or grazers (many sea urchins) and any change in their populations may affect the habitat structure and trophic fluxes inside this ecosystem [20]. For example, sea cucumbers remove and oxygenate the soft sediments by feeding, affecting the presence and abundance of other organisms that live or are influenced by sediment conditions.

Negative effects of hypersalinity have been found and demonstrated for other marine organisms [6-8], but to date, little is known about the effects of brine on echinoderms. Gacia et al. [5] also detected the total absence of echinoderms in the proximities of a desalination discharge, but they based their results in two surveys performed when the desalination plant was working for 16 years. In the present study, we have been able to compare the echinoderms communities before and after the disturbance has happened. This fact has permitted us to discriminate natural variations in these communities from changes induced by the brine effects. Moreover, in this study we have 
Table 3

Results of ANOVA testing for differences in echinoderms density (individuals per $\mathrm{m}^{2}$ ) through different sampling times (before desalination operation, $b=2003$, after with undiluted brine, au $=2004-2005$ and after with diluted brine, ad $=2006-$ 2011) at three studied stations

\begin{tabular}{lllllll}
\hline Source & $\mathrm{df}$ & $\mathrm{MS}$ & $F$ & $p$ & F vs. & SNK \\
\hline Time & 8 & 0.0137 & 4.7284 & $0.0000^{* * *}$ & Residual \\
Before-After undil.-After dil. & 2 & 0.0541 & 18.6552 & $0.0000^{* * *}$ & Residual \\
After undiluted brine $(=\mathrm{au})$ & 1 & 0.0015 & 0.5172 & $0.4727^{\text {ns }}$ & Residual \\
After diluted brine (=ad) & 5 & 0.0148 & 5.1034 & $0.0002^{* * *}$ & Residual \\
Station & 2 & 0.0641 & 22.1034 & $0.0000^{* * *}$ & Residual \\
Time $\times$ station & 16 & 0.0060 & 2.0754 & $0.0100^{*}$ & Residual \\
Bef.-After undil. - After dil. $\times$ station & 4 & 0.0233 & 8.0431 & $0.0000^{* * *}$ & Residual & $N_{\mathrm{b}}=N_{\mathrm{au}}=N_{\mathrm{ad}}$ \\
After undil. $\times$ station & 2 & 0.0015 & 0.5172 & $0.5968^{\text {ns }}$ & Residual & $D_{b}=D_{a d}>D_{a u}$ \\
After dil. $\times$ station & 10 & 0.0070 & 2.4034 & $0.0097^{* *}$ & Residual & $S_{\mathrm{b}}=S_{\mathrm{au}}=S_{\mathrm{ad}}$ \\
Residual & 243 & 0.0029 & & & &
\end{tabular}

Notes: $N=$ north; $D=$ desalination and $S=$ south. Only SNK results of the main interaction (in italics) are shown. df $=$ degrees of freedom, MS $=$ mean squares and ns $=$ not significant, ${ }^{*} p<0.05,{ }^{* *} p<0.01$ and ${ }^{* * *} p<0.001$.

monitored echinoderms populations for nine years, an extensive period when compared with other works regarding desalination impacts on the marine environment. In addition, during this nine-year period, the desalination plant has been enlarged and its brine has been diluted with seawater prior to discharge. This change in the discharge conditions has allowed us to detect a recuperation of the echinoderm densities where they have disappeared. Therefore, our observations confirm that echinoderm populations may be used as early indicators to monitor impacts associated with a desalination brine discharge, but also to detect a possible recovery of a previously impacted area when additional measures to dilute brine discharge have been implemented.

These results demonstrated that echinoderms are organisms extremely sensitive to salinity increments and may be used to prevent damage to key ecosystems like $P$. oceanica meadows. In this case, the disappearance of echinoderms induced the implementation measures (seawater bypassing to dilute the brine) before damage in the seagrass meadow was observed, but also may recover fast enough to detect the effectiveness of mitigation measures.

In this sense, when necessary and in order to minimize the environmental impact of desalination activity, it is feasible and effective to use, as a mitigation measure, the previous dilution of the brine with seawater has been observed in the present study.

\section{Acknowledgements}

This project was financially supported by the Water Consortium "Mancomunidad de Canales del
Taibilla". We also would like to thank Alicante Marina for the use of its equipment and facilities, as well as Aurora Garrote, Aitor Forcada, Yoana del Pilar, Marta Díaz-Valdés, Candela Marco, Santiago García, Rubén Olmo and Eleuterio Abellán who assisted in field data collection during all these years.

\section{References}

[1] P.H. Gleick, Water in crisis: Paths to sustainable water use, Ecol. Appl. 8 (1998) 571-579.

[2] M. Schiffler, Perspectives and challenges for desalination in the 21st century, Desalination 165 (2004) 1-9.

[3] Y. Fernández-Torquemada, J.L. Sánchez-Lizaso, J.M. González-Correa, Preliminary results of the monitoring of the brine discharge produced by the SWRO desalination plant of Alicante (SE Spain), Desalination 182 (2005) 395-402.

[4] N. Raventos, E. Macpherson, A. García-Rubiés, Effect of brine discharge from a desalination plant on macrobenthic communities in the NW Mediterranean, Mar. Environ. Res. 62 (2006) $1-14$.

[5] E. Gacia, O. Invers, M. Manzanera, E. Ballesteros, J. Romero, Impact of the brine from a desalination plant on a shallow seagrass (Posidonia oceanica) meadow, Estuar. Coast. Shelf Sci. 72 (2007) 579-590.

[6] Y. Del-Pilar-Ruso, J.A. De-la-Ossa-Carretero, F. Giménez-Casalduero, J.L. Sánchez-Lizaso, Spatial and temporal changes in infaunal communities inhabiting soft-bottoms affected by brine discharge, Mar. Environ. Res. 64 (2007) 492-503.

[7] Y. Del-Pilar-Ruso, J.A. De-la-Ossa-Carretero, A. Loya-Fernández, L.M. Ferrero-Vicente, F. Giménez-Casalduero, J.L. Sánchez-Lizaso, Assessment of soft-bottom polychaeta assemblage affected by a spatial confluence of impacts: Sewage and brine discharges, Mar. Pollut. Bull. 58 (2009) 765-786.

[8] R. Riera, F. Tuya, A. Sacramento, E. Ramos, M. Rodríguez, The effects of brine disposal on a subtidal meiofauna community, Estuar. Coast. Shelf Sci. 93 (2011) 359-365.

[9] M. Ahmed, W.H. Shayya, D. Hoey, J. Al-Handaly, Brine disposal from reverse osmosis desalination plants in Oman and the United Arab Emirates, Desalination 133 (2001) 135-147. 
AQ2 [10] N. Voutchkov, Salinity tolerance evaluation methodology for desalination plant discharge, Desalination and Water Treatment 1 (2009) 68-74.

[11] Y. Fernández-Torquemada, J.L. Sánchez-Lizaso, Monitoring of brine discharges from seawater desalination plants in the Mediterranean, Int. J. Environ. Res. Publ. Health 1 (2007) 449-461.

12] R.C. Brusca, G.J. Brusca, Invertebrates, Sinauer Associates, Sunderland, MA, 2003

[13] M. Sugni, D. Mozzi, A. Barbaglio, F. Bonasoro, M.D. Candia Carnevali, Endocrine disrupting compounds and echinoderms: New ecotoxicological sentinels for the marine ecosystem, Ecotoxicology 16 (2007) 95-108.

[14] M.P. Lloret-Oltra, J.L. Sánchez-Lizaso, Bioensayo para la evaluación de los efectos producidos por un incremento de la salinidad sobre la supervivencia del erizo de mar Paracentrotus lividus (Lamarck, 1816), Actas II Congreso Nacional AEDYR, Madrid, 2001 of Marine Benthos, Blackwell Scientific Publications, Oxford
[16] A.J. Underwood, Experiments in Ecology: Their logical design and interpretation using analysis of variance, Cambridge University Press, Cambridge, 1997.

[17] E. Irlandi, S. Macia, J. Serafy, Salinity reduction from freshwater canal discharge: Effects on mortality and feeding of an urchin (Lytechinus variegatus) and a gastropod (Lithopoma tectum), Bull. Mar. Sci. 61 (1997) 869-879.

[18] O. Basuyaux, M. Mathieu, C. Day, Effets de la salinité sur la consommation alimentaire et sur la croissance de l'oursin Paracentrotus lividus et de l'ormeau Haliotis tuberculata en élevage en circuit semi-fermé, Bull. Soc. Zool. Fr. 123 (1998) $141-150$.

[19] P.S. Asha, P. Muthiah, Effects of temperature, salinity and $\mathrm{pH}$ on larval growth, survival and development of the sea cucumber Holothuria spinifera Theel, Aquaculture 250 (2005) 823-829.

[20] V. Zupi, E. Fresi, A Study on the Food web of the Posidonia Oceanica Ecosystem: Analysis of the Gut Contents of Echinoderms, International Workshop on Posidonia oceanica Beds, G.I.S. Posidonie, Marseille, 1984. 1984. 